\title{
AVALIAÇÃO DA APRENDIZAGEM: UM ESTUDO COM BASE NAS PERCEPÇÕES DOS ALUNOS DO CURSO DE GRADUAÇÃO EM ADMINISTRAÇÃO
}

\author{
LEARNING ASSESSMENT: \\ A STUDY BASED ON THE PERCEPTIONS OF \\ UNDERGRADUATE MANAGEMENT STUDENTS
}

Recebido em: 09/01/2015 - Aprovado em: 20/03/2015

Avaliado pelo sistema double blind review

Editora Científica: Manolita Correia Lima DOI: $10.13058 /$ raep.2015.v16n2.237

\section{MARIANNY JESSICA DE BRITO SILVA marianny.jbrito@gmail.com RAQUEL SOUZA RAMOS}

UNIVERSIDADE FEDERAL DE PERNAMBUCO

\begin{abstract}
RESUMO
O artigo tem como objetivo identificar qual a percepção dos alunos do curso de graduação em Administração da Universidade Federal de Pernambuco (UFPE), Campus Agreste, sobre as formas avaliativas aplicadas por seus professores. Adotou-se uma abordagem metodológica quantitativa, utilizando-se de um questionário para alcançar o objetivo proposto, apresentando como amostra da pesquisa I55 estudantes. Os dados coletados e analisados revelaram que os estudantes em questão apontam as funções didáticas e burocráticas como motivos pelos quais se realiza uma avaliação e reconhecem sua importância apenas para o discente, ao representar um indicativo de desempenho. A maioria afirma que os sentimentos em relação aos processos avaliativos variam de acordo com o tempo de estudo e a empatia na disciplina e que a relação de ensino-avaliação geralmente é positiva. O feedback da avaliação é prática comum para estes alunos, mas não há diversidade de instrumentos de avaliação e, os que são utilizados, destoam com aqueles instrumentos desejados pelos estudantes. Concluise que, com base na percepção do aluno, é possível desenvolver uma reflexão pluralizada sobre os processos de avaliação, conduzindo melhorias nas práticas educacionais e na formação e treinamento de professores universitários.
\end{abstract}

Palavras-chave: prática educacional; avaliação da aprendizagem; percepção do aluno.

\begin{abstract}
This paper aimed to identify the perception of undergraduate Management course students from the Federal University of Pernambuco (UFPE), Agreste Campus, about their professors' assessment methods. A quantitative approach was employed through a questionnaire conducted on a research sample of 155 students. The data collected and analyzed revealed that the students in question pointed out didactic and bureaucratic functions as the reasons for undertaking assessments and recognized their importance only for students, as an indication of their performance. Most students stated that their feelings about the assessment processes vary according to their time of study and empathy for the discipline, and that the teaching-assessment ratio is generally positive. Assessment feedback was common practice for the sample, but there was a lack of diversity of assessment tools and those used clash with the ones they desired. In conclusion, according to the students' perception, it is possible to develop multiple thoughts about the assessment process, driving improvements in educational practices and the formation and training of university professors. Keywords: educational practice; learning assessment; students' perception.
\end{abstract}




\section{INTRODUÇÃO}

A avaliação é uma das etapas mais relevantes da prática educacional, pois busca analisar se o processo de ensino e aprendizagem está sendo alcançado. De maneira simplória,, este ato envolve o julgamento das ações, possibilitando decisões (LEITE; LIMA, 2008), de modo a assumir um papel estruturador na dinâmica da troca do conhecimento e no trabalho dos docentes e dos discentes (MARINHO; FERNANDES; LEITE, 20I4).

Apesar de sua importância ser reconhecida nos livros e artigos, no diaa-dia, o processo avaliativo ainda não é alvo de reflexão de boa parte dos professores inseridos em sala de aula. Ademais, muitos processos escolares se mantêm prisioneiros de práticas e instrumentos de avaliação voltados para classificações e resultados finais dos estudantes, em vez de estarem pautados em mecanismos que auxiliem no recolhimento de informações para apoiar a aprendizagem efetiva dos discentes (MARINHO; LEITE; FERNANDES, 20I2). É com base nesta segunda alternativa que é possível refletir e praticar a função formativa da avaliação. Esta enfatiza a importância do processo em detrimento do produto, reforçando a necessidade de ação do avaliador em prol do crescimento e desenvolvimento do avaliado (RIOS, 2005-2006). A avaliação formativa, proposta inicialmente por Scriven (1979), está pautada na busca por informações para melhoria do desempenho do aluno, só podendo existir baseado numa postura mais formativa do avaliador, ou seja, do professor. Esta postura engloba uma proximidade com os avaliados de modo a reconhecer as diferentes necessidades e dificuldades destes, compreendendo o processo avaliativo enquanto meio de interação e construção conjunta, existente em todo o processo de ensino e aprendizagem (ALONSO, 2005; BITENCOURT; SEVERO; GALLON, 2013).

No discurso de uma avaliação formativa, reconhece-se que esta existe como possibilidade, mas lamentavelmente não como prática (FERNANDES, 2009). A postura mais presenciada, especialmente no ensino superior, é a avaliação processada pela égide da lógica da classificação. Esta parece condenar os estudantes a desempenhos sofridos e sofríveis, pois, apesar do discurso a incentivar um exercício formativo, o que se percebe, ainda, em 
termos de avaliação, é a preocupação em separar o joio do trigo (SOUZA; BORUCHOVITCH, 2009). Isto posto, parece necessário a adoção de uma postura mais formativa, que possa auxiliar o aluno em sua aprendizagem efetiva, incentivando-o a seguir adiante.

Dentro desta perspectiva, é assentida a importância da percepção do estudante para contribuir nos avanços da visão e dos processos de avaliação. De acordo com pesquisas realizadas por Cox (1985), por exemplo, os discentes conseguem ter uma percepção clara a respeito deles mesmos, da maneira como desenvolvem suas práticas acadêmicas e os aspectos da avaliação que importam de fato. Eles são, portanto, indivíduos capazes de auxiliar na redução da lacuna existente entre os processos de ensino e avaliação, contribuindo com a escolha do educador acerca da avaliação a ser feita, de modo a revelar que a decisão pelo melhor processo deve ser tomada levando-se em consideração também aquele que é avaliado.

Ao compreender a relevância da percepção dos alunos para a melhoria do processo avaliatório, o presente artigo buscou identificar qual a opinião de alunos do curso de graduação em Administração da Universidade Federal de Pernambuco (UFPE), Campus Agreste, sobre as formas avaliativas aplicadas por seus professores. A facilidade de acesso a este local surge como principal justificativa para a realização da pesquisa no lócus em questão.

Com base nesta contextualização e da exposição do problema de pesquisa, mostram-se necessários aportes teóricos acerca do processo avaliativo tal como se presencia e como se idealiza, bem como, da percepção do aluno sobre esta prática educacional. As próximas duas seções trazem estas contribuições. Posteriormente, a metodologia adotada na pesquisa é descrita e os resultados e sua análise são realizados. Por fim, as principais conclusões do estudo são apontadas.

\section{A AVALIAÇÃO TAL QUAL SE TEM E COMO SE DESEJA}

Atentando para a forma tradicional de ensino, é possível perceber que a avaliação surge como um mecanismo a ser realizado em um momento determinado, separado do processo de aprendizagem, considerando o aluno como receptador passivo. O professor nesta realidade exerce uma postura de controle e autoritarismo, buscando muito mais desenvolver um aluno 
repetidor de conceitos do que crítico da realidade. Nesta configuração, o que se julga realmente é a capacidade de memorização, fazendo da avaliação um instrumento que gera medo e insegurança, inibidor de criatividade e realizador de frustações (LEITE; LIMA, 2008). Estes aspectos não podem fazer parte de uma prática maior que objetiva promover o crescimento e desenvolvimento das pessoas.

Como revelam Bitencourt, Severo e Gallon (2013, p. 2I2), "o processo avaliativo não pode se limitar à constatação da aprendizagem de conteúdos, com a mera utilização de provas e trabalhos (embora estes sejam parte do processo), porque o que está em jogo é a formação profissional do discente”. É necessário caminhar por outra estrada; identificar a avaliação como um processo contínuo, cumulativo e compreensivo, verificando mudanças e valorizando o desenvolvimento de habilidades e atitudes. Ela deve ser encarada como um processo formativo, onde o que conta é o saber, mais do que a classificação (PERRENOUD, 1999). Isto exige uma postura formativa do educador, mais próxima dos alunos, motivando-os com base em suas próprias carências intrínsecas, entendendo-os em relação a suas dificuldades e necessidades.

Para que esta relação seja a melhor possível, o professor precisa deixar claro os objetivos a serem alcançados com a disciplina, os padrões mínimos de desempenho esperados e as formas de medição que serão utilizadas, atentando também para as diferenças individuais de comportamento. O feedback é algo primordial neste processo, pois o educador é antes de mais nada um orientador que busca reforçar os acertos do aluno, dando-lhe autoestima para seguir adiante, e também identificar as falhas durante o processo de aprendizagem, gerando uma revisão e atualização mais eficiente. Como afirma Rabelo (1998):

Enquanto objeto com possibilidades diagnósticas, vinculada ao processo de ensino e de aprendizagem, precisamos elaborar um projeto de avaliação que em primeira instancia, e por meio dos instrumentos nele instituído, possa servir a todo instante como feedback para avaliar não só o aluno, seu conhecimento, mas também toda uma proposta da escola, possibilitando, assim, validar e/ ou rever o trabalho pedagógico a cada momento em que isto se fizer necessário (RABELO, I998, p.I2). 
Esta afirmação revela a necessidade de um relacionamento contínuo entre professor e aluno. Como afirma Alonso (2005), a qualidade do processo de aprendizagem tem como elemento catalizador a convivência. Dentro deste processo, a avaliação e suas etapas devem ser vistas como fontes de interação e construção conjunta, presente durante toda a prática educativa. Fazendo da avaliação uma prática indissociável do ensino presente não só ao final, mas durante todo o processo de ensino e aprendizagem (BITENCOURT; SEVERO; GALLON, 20I3), esta etapa educacional passa a ser vista como uma fase natural e necessária para direcionar o aprendizado e desenvolver a realização pessoal, além da simples ponderação do conhecimento.

De acordo com o que já foi exposto, é percebido que a avaliação como se deseja parte dos princípios norteadores propostos por Grillo e Gessinger (20Io), descritos da seguinte maneira: a) a forma de avaliação adotada pelo professor implicará na maneira como este ensinará o conteúdo; b) a avaliação deve estar presente em todo o processo de ensino e aprendizagem e; c) exige uma contínua interação entre professor e aluno. Estes princípios orientam uma postura formativa que busca conhecer o real nível de aprendizado do aluno, servindo como diagnóstico em prol de uma reorientação, por parte do professor, da aprendizagem. Vale ressaltar, portanto, que a avaliação está relacionada ao processo de verificação da aprendizagem dos discentes, mas também a verificação da qualidade da atuação do docente (COVATTI; FISCHER, 20I2). Esta verificação está intimamente relacionada à percepção, tema tratado na seção abaixo.

\section{A PERCEPÇÃO DO ALUNO NO PROCESSO DE AVALIAÇÃO}

Todos os indivíduos apresentam percepções sobre os mais diversos aspectos e comportamentos que os cercam. Elas representam uma interpretação singular de uma situação, caracterizadas enquanto processos cognitivos e subjetivos de obtenção de informações para dar sentido ao mundo (ROBBINS, 2005).

No ambiente educacional, a importância da percepção do aluno sobre o processo de aprendizagem foi sendo reconhecida após o artigo seminal de Warren (1987). Nele, o autor, por meio dos depoimentos dos estudantes, 
identificou que a aprendizagem mais importante é aquela que vai além da mera aquisição de informações; que os testes objetivos de múltipla escolha ou de resposta breve são inadequados e que as informações obtidas pelos professores sobre a aprendizagem não condizem com o que ela expressa na realidade.

Ainda nesta pesquisa, Warren (1987) percebeu que os alunos valorizam os processos mais informais onde as situações de ensino e avaliação estão integradas. Outros autores, como, por exemplo, Boud (1990), deram continuidade às premissas destacadas por Warren e desenvolveram seus trabalhos com base na importância de uma mudança na visão estreita e não instrumental do aprendizado proposto pela forma tradicional de ensino desencadeada também na avaliação.

A falta de coordenação entre o que é realmente aprendido e o que é cobrado em avaliações também ganhou destaque na atmosfera dos estudos educacionais. Segundo Lewis (199I), este problema acaba passando para o aluno a ideia de que a prova não testa o que eles realmente aprenderam em sala. Os estudantes, portanto, passam a apontar a avaliação como falha, incompleta, ineficiente e inadequada.

No Brasil, um dos estudos mais importantes sobre a percepção do aluno em relação à avaliação é o de Godoy (2000). Por meio de uma abordagem metodológica qualitativa, o autor entrevistou 13 alunos, além de receber depoimentos escritos de 98 estudantes. Seus resultados trouxeram a definição de conjuntos de análises que, neste artigo, merecem destaque, pois foi com base neles que esta pesquisa foi realizada. As categorias descritas por Godoy (2000) são enumeradas em sete:

- Motivos pelos quais se avalia -> os motivos podem ser identificados por meio de cinco funções básicas; são elas: função burocrática, função didática, função de acompanhamento de ensino, função de controle e função de garantia do desempenho profissional (GODOY, 1995);

- Importância da avaliação -> a avaliação pode ser vista como importante ou não na percepção do aluno. Se esta for vista como importante, ainda deve envolver para quais envolvidos ela apresenta esta característica;

- Sentimentos a respeito do processo avaliativo -> os sentimentos sobre a avaliação podem ser negativos ou positivos, a depender de 
fatores como motivação, empatia pela disciplina, concordância com a forma de avaliação adotada, horas estudadas e aspectos emocionais no instante da avaliação;

- Técnicas e instrumentos de avaliação -> geralmente há uma diferenciação entre as técnicas mais adotadas pelos professores das que os alunos têm preferência. O que é importante ressaltar é que o professor deve buscar diversificar seus instrumentos, pois a utilização repetida e exclusiva de um mesmo tipo de instrumento de avaliação não permite ver o indivíduo sob todos os ângulos, o que pode induzir em erros graves (BARBOSA; ALAIZ, 1994). Além disto, alguns instrumentos são mais adequados para certos alunos do que para outros; assim a variação de técnicas proporciona que todos os tipos de estudantes possam ser atingidos (MASETTO, 20I2). De maneira geral, muitos instrumentos de avaliação podem ser utilizados como, por exemplo, trabalhos, provas objetivas, provas discursivas, provas orais, relatórios de observação, participação em aula, seminários e debates; cada um deles, apresentando suas possibilidades e limitações. É importante considerar que estes instrumentos devem ser escolhidos com base nos objetivos pedagógicos seguidos pelo docente, no perfil de cada aluno envolvido neste processo e nas técnicas de ensino utilizadas pelo professor;

- Discussão dos resultados da avaliação -> Após realização da avaliação, podem existir ou não feedback por parte dos professores. Ele é um elemento importante na reorganização da prática de ensino e aprendizagem, pois auxilia o docente a repensar sua conduta perante a disciplina e os alunos. De modo especial, oferece informações para que o estudante supere suas dificuldades e para que o professor o auxilie nesta tarefa (MASETTO, 20I2). O nível deste feedback também deve ser levado em consideração, pois há uma diferença significante entre o docente que debate o instrumento de avaliação e os resultados que este mediu para aquele professor que apenas apresenta as notas aos estudantes. A primeira postura representa, de fato, o conceito de feedback no processo avaliativo defendido neste artigo; 
- Avaliação enquanto mecanismo legitimador do conhecimento -> a percepção do aluno auxilia na compreensão se a avaliação é capaz ou não de refletir o conhecimento adquirido;

- Relação ensino-avaliação -> a avaliação pode pedir os mesmos níveis de conhecimento apresentados na sala ou exigir mais ou menos daquilo que foi apresentado durante as aulas;

Com base nesta categorização é possível desenvolver estudos para obter uma compreensão geral da percepção do aluno acerca da forma como ele é avaliado, de modo a sugerir melhorias das práticas avaliativas adotadas pelos docentes.

\section{PROCEDIMENTOS METODOLÓGICOS}

Adotando uma abordagem metodológica quantitativa, a presente pesquisa desenvolveu, com base nas categorias elencadas por Godoy (2000), um questionário (vide Apêndice A) que buscou obter informações sobre as percepções de alunos do curso de graduação em Administração. Como ambiente de pesquisa, adotou-se a Universidade Federal de Pernambuco, Centro Acadêmico do Agreste (CAA), localizada na cidade de Caruaru. Este centro representa o primeiro campus da UFPE no interior, tendo sido inaugurado em 2006 (UFPE, 20I4). O curso de Administração do campus veio juntamente com a implantação deste na cidade.

No ano de 20I4, o CAA prestou serviços educacionais a 3.609 alunos espalhados pelos cursos de Graduação em Administração, Economia, Engenharia Civil, Engenharia de Produção, Design, Pedagogia, Educação Intercultural, Medicina além das Licenciaturas em Matemática, em Física e em Química. Especificamente no curso de Administração, ofertado nos turnos da manhã e da noite, têm-se o total de 670 estudantes ${ }^{\mathrm{I}}$.

Com base neste universo, adotou-se como amostra 193 estudantes de graduação em Administração, tendo um nível de confiança de $90 \%$ e um erro amostral de 5\%. Entretanto, após análise, apenas 155 questionários foram validados, pois 38 deles foram respondidos indevidamente ou não traziam todas as respostas. Com base neste cenário, o nível de confiança se manteve (90\%), mas o erro amostral passou a ser de 5,8\%. Adotando uma 
amostra de 155 alunos, as características observadas foram: 44,5\% (total de 69) dos indivíduos que formam a amostra são do gênero masculino e 55,5\% (total de 86) são do gênero feminino. A faixa etária dos estudantes esteve concentrada no intervalo de I8 a 24 anos por representar $82,58 \%$ (total de I28) da amostra, com média de 2I,95 e desvio padrão de 4,026.

Referente ao período cursado pelos indivíduos da amostra, cerca de 57,4\% (total de 89) dos estudantes fazem o I $4^{\circ}$ ou $9^{\circ}$ período (Tabela I). Quanto ao turno, 56,8\% (total de 88) da amostra cursa Administração no turno da manhã e 43,2\%, da noite (total de 67).

Estas são, portanto, as características gerais da amostra.

Tabela I Distribuição da amostra por período de curso

\begin{tabular}{|lll|}
\hline Periodo & Frequência & Percentual (\%) \\
\hline $1^{\circ}$ & 19 & 12,3 \\
\hline $2^{\circ}$ & 15 & 9,7 \\
\hline $3^{\circ}$ & 10 & 6,5 \\
\hline $4^{\circ}$ & 36 & 23,2 \\
\hline $5^{\circ}$ & 11 & 7,1 \\
\hline $6^{\circ}$ & 7 & 4,5 \\
\hline $7^{\circ}$ & 12 & 7,7 \\
\hline $8^{\circ}$ & 10 & 6,5 \\
\hline $9^{\circ}$ & 34 & 21,9 \\
\hline Erro & 1 & 0,6 \\
\hline Total & $\mathbf{1 5 5}$ & $\mathbf{1 0 0} \%$ \\
\hline
\end{tabular}

\section{ANÁLISE E DISCUSSÃO DOS RESULTADOS}

Partindo-se da necessidade de compreender a percepção do aluno sobre o processo avaliativo do qual faz parte e, assim, trazer informações que venham a contribuir para o desenvolvimento de uma avaliação formativa, o presente artigo coletou e analisou as afirmações dadas por estudantes do curso de graduação em Administração, separando-as em sete categorias de análise, as mesmas apontadas por Godoy (2000) em seu trabalho de natureza qualitativa. Elas e os seus resultados são apontados nesta seção. 


\section{Motivos pelo qual se avalia}

Entre os motivos pelos quais se avalia, a maioria dos estudantes da amostra reconheceu a função didática do processo avaliativo. 54,8\% (total de 85 alunos) deles consideram que a aplicação de uma avaliação serve para identificar se os alunos estão ou não entendendo a matéria dada, ou seja, serve para avaliar o grau de conhecimento. Como afirma Godoy (1995), esta função auxilia os docentes para saber, avaliar, ver, verificar, medir, testar a aprendizagem, o conhecimento ou o conteúdo ensinado. Ela aponta a avaliação como fonte de informações sobre o grau de conhecimento adquirido pelo aluno, elemento básico para a mudança ou a continuidade do instrumento avaliativo. Mesmo assim, segundo Bitencourt, Severo e Gallon (2013), a avaliação não pode se limitar à constatação da aprendizagem de conteúdos; é necessária uma reflexão e uma utilidade maior.

A função burocrática da avaliação também foi destacada como motivo pelo qual se avalia. Segundo 40 estudantes (referentes a 25,8\% da amostra), o processo avaliativo surge como uma exigência externa, onde os professores devem apresentar notas à Universidade e, assim, seguir as normas de ensino. A função burocrática apontada por estes discentes como principal motivo pelo qual se avalia revela uma percepção da avaliação como um processo apenas oficial que emerge das premissas do ensino tradicional de aprendizagem, de pontualidade e separação entre ensino e avaliação, sem a preocupação se este processo está sendo alcançado de fato (LEITE; LIMA, 2008).

Ademais, $8,4 \%$ da amostra (total de I3) reconhece a função de acompanhamento do ensino. Isto significa que a avaliação é realizada com o motivo de compreender se a maneira com que o professor está lecionando está sendo assimilada pelos alunos. Esta função destaca, portanto, o caráter estruturador do processo de ensino e aprendizagem (MARINHO; FERNANDES; LEITE, 20I4) e a busca por reflexão do professor em relação aos seus métodos de ensino, característica essencial para uma reflexão na e sobre a ação apontada por Schön (2000).

Apenas $6,5 \%$ dos estudantes consideram a avaliação como um instrumento para medir a qualidade do desempenho futuro, ou seja, identificar o 
aprendizado para a possibilidade de sucesso profissional. Por fim, 4,5\% dos alunos vem na avaliação um mecanismo de controle. Nesta percepção, o processo avaliativo é visto como um instrumento para prender a atenção do aluno, fazê-lo estudar, causar ansiedade e medo, sendo, portanto, descrito como inibidor de criatividade e realizador de frustações (LEITE; LIMA, 2008).

Notou-se que os estudantes, em sua maioria, percebem a avaliação como elemento que testa seus conhecimentos, não englobando a visão de que a mesma também serve como ferramenta de julgamento para o professor e sua prática de ensino, para a reflexão do docente e melhoria do processo de ensino e aprendizagem como um todo. Ademais, a compreensão do instrumento avaliativo como exigência burocrática por um número considerável de estudantes reforça a percepção tida pelos discentes de que o professor se encontra menos envolvido com a avaliação enquanto elemento formativo, servindo apenas como documento oficial necessário para a instituição. As informações aqui analisadas podem ser observadas na Tabela 2.

Tabela 2 Motivos pelos quais se avalia

\begin{tabular}{|lll|}
\hline Funções que motivam a Avaliação & Frequência & Percentual (\%) \\
\hline Função Didática & 85 & 54,8 \\
\hline Função Burocrática & 40 & 25,8 \\
\hline Função de acompanhamento de ensino & 13 & 8,4 \\
\hline Função de Controle & 7 & 4,5 \\
\hline Função de qualidade de desempenho futuro & 10 & 6,5 \\
\hline Total & 155 & $100 \%$ \\
\hline
\end{tabular}

\section{Importância da avaliação}

Na amostra analisada, 97,5\% dos estudantes consideram a avaliação como um aspecto importante do processo de ensino e aprendizagem. Apesar desta concordância, os alunos apresentam divergências quando explicitam o porquê. 
Um número de 8I estudantes (referente a 52,3\% da amostra) a consideram importante somente para o próprio aluno, pois possibilita analisar o seu desempenho. Já 6I indivíduos que compõem a amostra (referentes a 39,4\%) compreendem a avaliação como um processo importante para o professor e para o aluno. Esta percepção se aproxima da ideia de avaliação formativa e emancipatória, onde ambos os agentes envolvidos na atividade reconhecem a importância da mesma para os seus desenvolvimentos (GONÇALVES, 20I2).

Ademais, I,3\% (total de dois estudantes) da amostra considera a avaliação importante apenas para o aluno por uma questão de impacto no currículo e 4,5\% (total de sete discentes) a percebem como importante apenas para o professor. Esta última pode estar relacionada às funções burocráticas, de controle e de acompanhamento no ensino propostas por Godoy (2000).

Uma avaliação formativa e emancipatória deve ser percebida por estudantes e professores como elemento crucial na construção do processo de ensino e aprendizagem, influenciando ambos. Notou-se que, apesar de um número considerável de estudantes perceber esta duplicidade do processo, a maioria dos discentes analisados visualiza o instrumento avaliativo como importante para um único envolvido no processo, seja aluno ou professor. A Tabela 3 reflete os dados aqui descritos.

Tabela 3 Importância da avaliação

\begin{tabular}{|lll|}
\hline Importância da Avaliação & Frequência & Percentual (\%) \\
\hline Não é importante & 4 & 2,6 \\
\hline $\begin{array}{l}\text { Importante para o aluno, pois } \\
\text { mede o seu desempenho }\end{array}$ & 81 & 52,3 \\
\hline $\begin{array}{l}\text { Importante para o aluno, pois } \\
\text { impacta no currículo }\end{array}$ & 2 & 1,3 \\
\hline $\begin{array}{l}\text { Importante para o professor } \\
\text { Importante para aluno e } \\
\text { professor }\end{array}$ & 7 & 4,5 \\
\hline \begin{tabular}{l} 
Total \\
\hline
\end{tabular} & 61 & 39,4 \\
\hline
\end{tabular}




\section{Sentimentos a respeito do processo avaliatório}

A grande maioria dos alunos que compõem a amostra afirma que os sentimentos a respeito da avaliação variam em proporção ao quanto se foi estudado e a empatia pela disciplina. $65,2 \%$ (total de ror discentes) dos envolvidos reconhecem, portanto, que aspectos ligados à motivação na aprendizagem vão influenciar a forma como eles se portam mediante um processo de avaliação. Esta constatação chama atenção por revelar que, para a maioria, os sentimentos relacionados à avaliação emanam de características e decisões ligadas ao indivíduo, mas também à empatia pela disciplina que pode estar relacionada, além dos seus gostos particulares, ao professor em si, a forma de transmissão de conteúdo adotada e a interação com a turma. Com base nesta percepção, é reconhecida a importância do relacionamento entre todos os que fazem parte do processo de ensino e aprendizagem, considerando a convivência como elemento catalizador de suas práticas (ALONSO, 2005).

Apesar disto, 36 estudantes (referentes a $23,2 \%$ da amostra) afirmam sempre apresentar sentimentos negativos em relação à avaliação, seja porque ficam nervosos e angustiados ( $13,5 \%$ ) ou porque não concordam com a forma de avaliação que é aplicada (9,7\%). Estas considerações reafirmam a ideia da avaliação como um instrumento que gera medo, insegurança e frustações (LEITE; LIMA, 2008).

Por fim, apenas $1 \mathrm{I}, 6 \%$ da amostra (total de i8 estudantes) apresenta, independente do grau de estudo ou empatia, sentimentos positivos em relação aos processos avaliatórios. Destes, II\% (total de I7) a consideram uma atividade normal, tranquila e que se constitui em apenas mais uma tarefa na rotina. Esta percepção reflete aspectos de uma avaliação formativa e continuada ressaltada por Fernandes (2009).

De maneira simplificada, as informações relacionadas aos sentimentos a respeito do processo avaliatório são apresentadas na Tabela 4 . 
Tabela 4 Sentimentos dos estudantes a respeito do processo avaliatório

\begin{tabular}{|c|c|c|}
\hline Sentimentos sobre a avaliação & Frequência & Percentual (\%) \\
\hline Negativo: angústia e nervosismo & 21 & 13,5 \\
\hline Negativo: raiva por forma de avaliação adotada & 15 & 9,7 \\
\hline $\begin{array}{l}\text { Varia de acordo com tempo de estudo e empatia pela } \\
\text { disciplina }\end{array}$ & 101 & 65,2 \\
\hline Positivo: avaliação é atividade normal & 17 & 11,0 \\
\hline $\begin{array}{l}\text { Positivo: gosto das formas de avaliação e me sinto } \\
\text { motivado }\end{array}$ & 1 & 0,6 \\
\hline Total & 155 & $100 \%$ \\
\hline
\end{tabular}

Buscou-se analisar também a relação entre o gênero dos estudantes e os seus sentimentos a respeito do processo avaliativo. Foi percebido que cerca de $68,6 \%$ da amostra feminina (59 estudantes) e $60,87 \%$ da amostra masculina (42 discentes) apontam que seus sentimentos em relação a avaliação variam de acordo com o tempo de estudo e a empatia pela disciplina. Esta constatação reforça a importância dos aspectos individuais na determinação do sentimento em relação à avaliação e a importância do gosto pela disciplina que pode ser influenciada por aspectos externos, sociais, sendo esta visão apoiada pela maioria das mulheres e dos homens.

Os sentimentos negativos, entretanto, variam entre os gêneros. I8 alunas apontam sentimentos negativos (cerca de 21 $\%$ da amostra feminina), seja por nervosismo ( $15, \mathrm{I} 2 \%)$ ou por raiva (5,81\%). Já $26, \mathrm{I} \%$ da amostra masculina (I8 estudantes) revela que sentimentos negativos são presenciados no processo de avaliação, principalmente devido à raiva pelo tipo de avaliação adotada (I4,5\%) e, em outros casos, pela angústia e nervosismo causado pelo processo (II,6\%). Ademais, um maior percentual dos homens tem sentimentos positivos a respeito do processo avaliativo em comparação ao percentual feminino. Cerca de $13 \%$ da amostra masculina (nove alunos) considera a avaliação como uma atividade normal (II,59\%) ou ainda como instrumento de motivação (I,45\%); já entre as mulheres, nenhuma delas vê este instrumento como motivador, mas 10,47\% da amostra feminina (nove mulheres) considera a avaliação uma atividade normal que gera sentimentos positivos. Esta diferença entre os gêneros pode estar relacionada a capacidade da avaliação em requerer certas 
habilidades que estão naturalmente mais relacionadas a um determinado gênero. O Gráfico I apresenta os dados aqui analisados.

Com base nos dados apresentados, o que se está querendo reforçar é que se faz necessário uma compreensão do professor da diversidade de indivíduos presentes em sala de aula enquanto agentes ativos e únicos do processo de ensino e aprendizagem (GONÇALVES, 20I2), que deve ser considerada em termos de gênero, comportamento, percepção e necessidades de aprendizagem.

Gráfico I Relação entre sentimento em relação ao processo avaliativo e o gênero dos estudantes

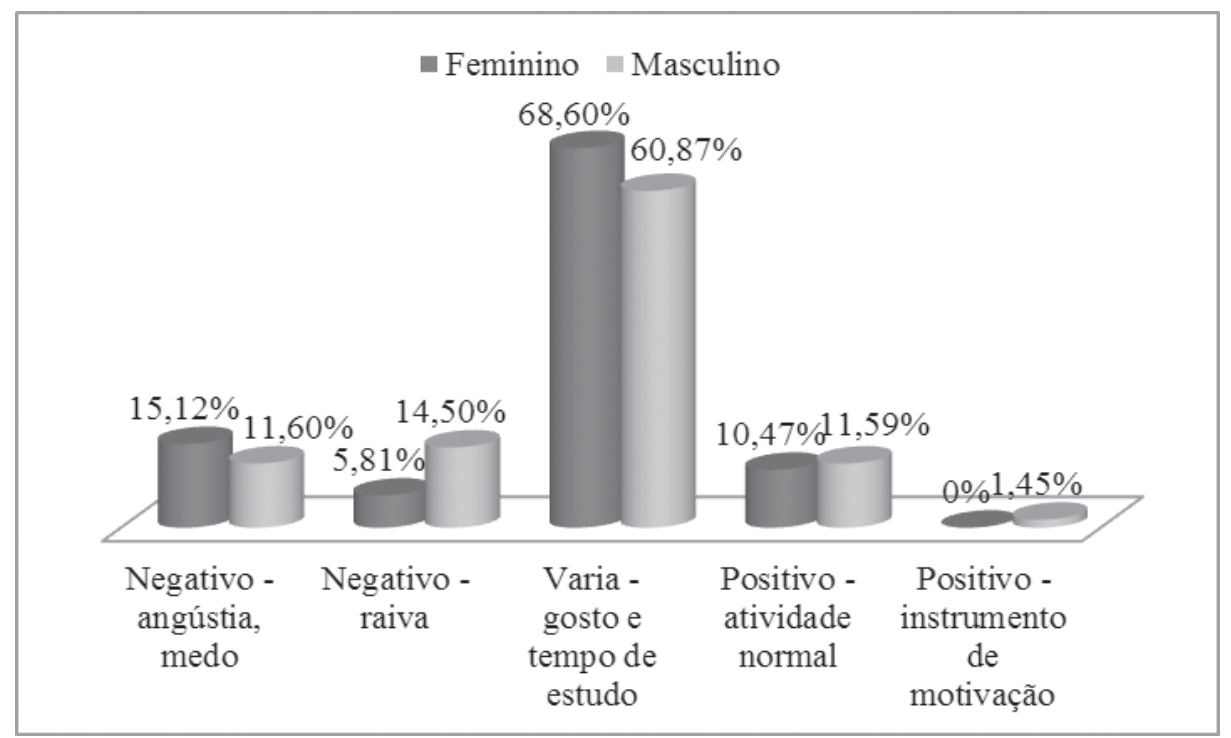

\section{Técnicas e instrumentos de avaliação}

Com base nos dados coletados por meio do questionário, foi constatado que a prova escrita é a forma mais comum de avaliação aplicada pelo professor no curso de Graduação em Administração do CAA, sendo apontada por I39 dos estudantes em análise (referentes a $89,7 \%$ da amostra), seguida dos trabalhos como relatórios e projetos com $6,5 \%$ e, posteriormente, seminários com 3,9\% (Tabela 5). 
O que deve ser ressaltado por meio da análise, entretanto, é a escolha por pouca diversidade de instrumentos adotados pelos docentes. Entre os cinco pontuados pelo questionário, apenas três instrumentos foram selecionados como métodos utilizados com maior frequência durante a graduação. Isto não significa necessariamente que os demais instrumentos não são utilizados, mas sim que não são oferecidos na mesma proporção que as outras técnicas, de modo a reforçarem um estilo padrão e engessado dos mecanismos a serem utilizados no processo de avaliação, diminuindo a possibilidade da criação de novos meios para avaliar os estudantes. Esta realidade é preocupante, pois como revela Barbosa e Alaiz (I994), um instrumento exclusivo e repetitivo pode não favorecer aos alunos que apresentam competências relevantes que não são medidas com base em um único instrumento adotado pelo docente. É preciso diversificar.

Tabela 5 Forma mais comum de avaliação adotada pelos professores

\begin{tabular}{|lll|}
\hline Forma mais comum de avaliação & Frequência & Percentual (\%) \\
\hline Prova escrita & 139 & $\mathbf{8 9 , 7}$ \\
\hline Trabalhos & 10 & 6,5 \\
\hline Seminários & 6 & 3,9 \\
\hline Provas Orais & 0 & 0 \\
\hline Participação e frequência em sala & 0 & 0 \\
\hline Total & $\mathbf{1 5 5}$ & $\mathbf{1 0 0 \%}$ \\
\hline
\end{tabular}

Outra consideração que deve ser feita é o tipo de avaliação que os alunos preferem. As respostas revelam que a preferência é diversificada, onde 4I, 9\% (total de 65) da amostra tem como instrumento de avaliação preferido os trabalhos como projetos e relatórios, seguidos de $24,5 \%$ (total de 38 ) que preferem seminários, 2I,3\% (total de 33) com preferência pela prova escrita, (II,6\% total de I8) que consideram a presença e participação em aula como instrumento preferido e, por fim, menos de $\%$ (total de um) que apontam preferência pela prova oral. Esta constatação reforça a necessidade de diversificação dos instrumentos avaliativos, ressaltando a ideia de que a boa avaliação não pode ser uma ferramenta que busca homogeneidade, mas sim 
o meio para compreender os avanços individuais e do grupo envolvidos no processo de aprendizagem (COVATTI; FISCHER, 20I2). O Gráfico 2 traz uma melhor visualização da comparação entre os instrumentos de avaliação mais usados pelos professores e os preferidos pelos alunos.

Gráfico 2 Comparação entre o tipo de instrumento de avaliação mais comum adotado por professores e o preferido pelos alunos

\section{- Mais comum Preferida}

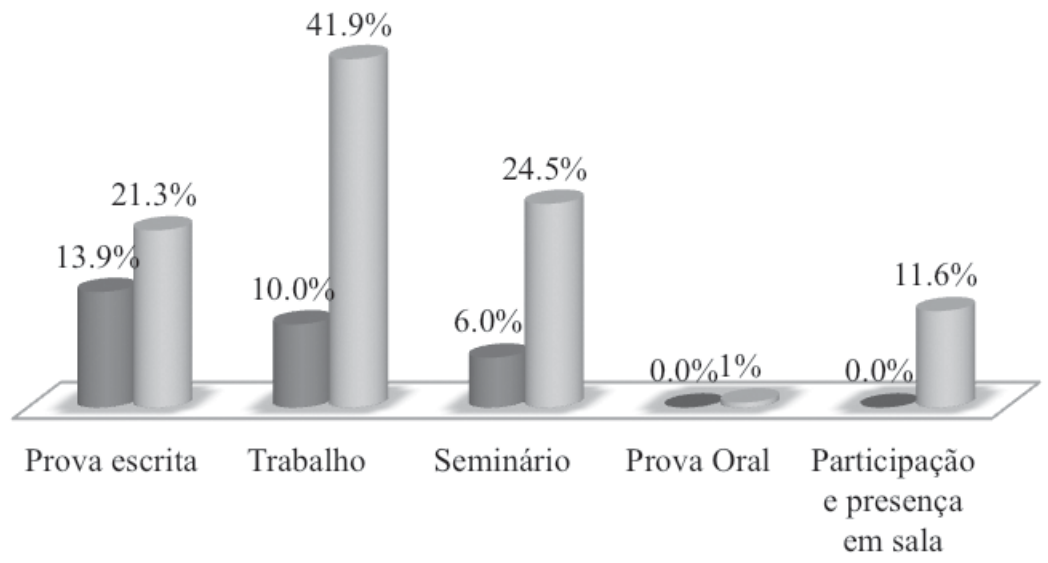

Outro aspecto que se buscou compreender é o quanto estes instrumentos considerados pelos discentes como mais comuns de serem aplicados pelos professores podem ou não refletir o conhecimento adquirido. Para isso, realizou-se a análise cruzada destas questões ( $4^{\mathrm{a}}$ pergunta do questionário versus $7^{a}$ pergunta do questionário). Foi percebido que em relação à prova escrita, 76 estudantes analisados $(54,7 \%$ da amostra que apontou este instrumento de avaliação como o mais comum) consideraram que este mecanismo é capaz de aferir o conhecimento a depender da técnica avaliativa (letra b), da qualidade das questões, da elaboração da prova e de como esta será avaliada (letra e). Ademais, $22,3 \%$ da amostra que apontou a prova escrita como mais comum (3I discentes) ressaltou a incapacidade 
de este instrumento refletir o conhecimento adquirido devido à dedicação dos alunos a temas específicos que podem não serem exigidos na prova (letra c). Todos estes elementos indicam que a prova escrita, para ser de fato um instrumento auxiliador do processo de avaliação formativa, demanda do professor um maior cuidado e reflexão sobre aquilo que será exigido e de forma esta exigência deverá ser colocada para o aluno, de modo a gerar melhorias no processo de ensino e aprendizagem, não buscando simplesmente separar o joio do trigo (SOUZA; BORUCHOVITCH, 2009), mas integrar o aluno, auxiliando-o na superação de suas deficiências.

Em relação aos trabalhos como instrumentos de avaliação, as mesmas características da prova escrita foram observadas, ou seja, a capacidade de medir o conhecimento deste mecanismo depende de como ele é organizado e desenvolvido pelo professor (letras b e e) para 50\% da amostra (cinco estudantes) e para 30\% dos estudantes (três discentes), os trabalhos não refletem o conhecimento, pois não é compatível com o que o discente estuda (letra c). O mesmo é apresentado pelos seminários; 50\% da amostra (três estudantes) revela a importância de como o seminário é organizado e avaliado (letras b e e) e 33,3\% dela não aponta os seminários como mecanismo de reflexão do conhecimento devido à incompatibilidade entre o que foi estudado e o que foi exigido pelo seminário. A Tabela 6 apresenta estes dados.

Assim, percebeu-se que a capacidade de refletir o conhecimento não está relacionada diretamente a escolha do instrumento de avaliação em si, mas a capacidade do docente de desenvolvê-lo de acordo com os objetivos que já devem ter sido explanados e debatidos com os estudantes, exigindo conhecimentos nos mesmos níveis e natureza dos apresentados em sala de aula, reconhecendo a importância do estudante no processo avaliativo, a fim de gerar interação e construção conjunta (BITENCOURT; SEVERO; GALLON, 20I3). Por meio desta análise, é reforçada a necessidade de ação do avaliador em prol do crescimento e desenvolvimento do avaliado (RIOS, 2005-2006). 
Tabela 6 Tipo de avaliação mais comum versus capacidade de medir conhecimento

\begin{tabular}{|lllll|}
\hline & \multicolumn{2}{c}{ Avaliação mais comum } & Total \\
\cline { 2 - 2 } & A & B & C & \\
$\begin{array}{l}\text { Capacidade de medir } \\
\text { conhecimento }\end{array}$ & & & & \\
\hline A & 18 & 1 & 1 & 20 \\
\hline B & 35 & 2 & 2 & 39 \\
\hline C & 31 & 3 & 2 & 36 \\
\hline D & 14 & 1 & 0 & 15 \\
\hline E & 41 & 3 & 1 & 45 \\
\hline Total & $\mathbf{1 3 9}$ & $\mathbf{1 0}$ & $\mathbf{6}$ & $\mathbf{1 5 5}$ \\
\hline
\end{tabular}

\section{Discussão dos resultados da avaliação}

Um dos elementos mais importantes no processo de avaliação é a existência do feedback em relação aos resultados alcançados (RABELO, 1998). Indagados sobre este elemento, 33,5\% dos estudantes que compõem a amostra (total de 52) afirmaram que os professores, após a avaliação, entregam a prova, o trabalho ou a nota e aguardam questionamentos, dúvidas ou considerações dos alunos. É perceptível nesta realidade, portanto, que o processo de feedback só acontece caso o aluno tenha algo a questionar. Nesta situação, a simples entrega do instrumento avaliativo com seu resultado já representa mecanismo suficiente na construção dos pontos a serem melhorados pelo aluno. Na visão de Rabelo (1998), entretanto, este tipo de postura não condiz com uma atividade que possa gerar uma revisão e atualização mais eficiente. São necessárias discussão e reflexão dos resultados alcançados.

A maioria dos estudantes, entretanto, correspondentes a $47,7 \%$ da amostra (total de 74 discentes), afirma que os professores realizam o feedback, dialogando em sala de aula com os alunos sobre as questões da prova ou os demais instrumentos avaliativos aplicados, podendo disponibilizar a nota do estudante naquele momento $(27,1 \%)$ ou colocá-la na plataforma virtual da instituição - SIGA (20,6\%). Nesta realidade, o feedback representa um ato 
de comunicação, motivação e aprendizagem (FLORES, 2009) que auxilia na construção e efetivação da avaliação formativa.

I9 alunos (referentes a I2,3\% da amostra) ainda revelam que os professores apenas falam as notas e Io estudantes (referentes a 6,5\% da amostra) garantem que os professores não realizam nenhum tipo de feedback. A falta desta prática compromete todo o processo de ensino e aprendizagem tal como Fernandes (2009) sugere. Os dados aqui analisados estão apresentados na Tabela 7.

Tabela 7 Comportamento dos professores no processo de feedback da avaliação

\begin{tabular}{|lll|}
\hline $\begin{array}{l}\text { Comportamento do professor } \\
\text { no feedback }\end{array}$ & Frequência & Percentual (\%) \\
\hline $\begin{array}{l}\text { Discutem a prova e falam a nota } \\
\text { Discutem a prova, mas não }\end{array}$ & 42 & 27,1 \\
\hline falam a nota & 32 & 20,6 \\
\hline $\begin{array}{l}\text { Apenas falam a nota } \\
\text { Entregam a avaliação e esperam } \\
\text { questionamentos dos alunos }\end{array}$ & 52 & 12,3 \\
\hline $\begin{array}{l}\text { Não discutem a avaliação nem } \\
\text { falam a nota do aluno }\end{array}$ & 10 & 33,5 \\
\hline \begin{tabular}{l} 
Total \\
\hline
\end{tabular} & 155 & 6,5 \\
\hline
\end{tabular}

\section{Avaliação enquanto mecanismo legitimador do conhecimento}

Existiu certa diversidade na percepção dos alunos que compõem a amostra acerca da avaliação enquanto mecanismo que reflete o conhecimento aprendido. $29 \%$ dos estudantes (total de 45 discentes) acreditam que avaliações refletem ou não o conhecimento a depender da qualidade das questões, da elaboração e do critério adotado pelo professor. Atrelado a esta realidade, $25,2 \%$ da amostra (total de 39 ) afirma que a avaliação pode medir o conhecimento do aluno a depender da técnica de avaliação escolhida. Estas percepções reforçam a importância da reflexão do educador em relação ao tipo de disciplina, o perfil da turma, o tipo de avaliação a ser adotado e a forma de aquisição de conhecimento a ser incentivado (BARBOSA; ALAIZ, I994; SCHÖN, 2000; LEITE; LIMA, 2008; FERNANDES, 2009). 
Por outro lado, expressivos $23,2 \%$ (total de 36 ) dos alunos consideram que a avaliação não mede o conhecimento, pois às vezes os estudantes se dedicam a temas específicos que não são abordados pelos professores na avaliação. Já 9,7\% dos estudantes (total de I5) reafirmam a incapacidade de medir conhecimento da avaliação por causa dos aspectos emocionais que podem impactar negativamente no resultado da mesma. Estas duas constatações revelam que: I) os objetivos da avaliação não estão claramente compreendidos pelo estudante ou até mesmo não foram repassados a este e que, 2) a avaliação está associada, para estes discentes, a um instrumento de punição, que inibe suas capacidades de externar suas aprendizagens gerando medo e angústia.

20 alunos (referentes a $\mathrm{I} 2,9 \%$ da amostra), entretanto, consideram que, no geral, a avaliação é capaz de refletir o conhecimento aprendido, independente do instrumento ou elementos adotados. Estes percentuais podem ser vistos na Tabela 8 .

Tabela 8 Capacidade da avaliação em medir o conhecimento adquirido

\begin{tabular}{|c|c|c|}
\hline $\begin{array}{l}\text { Capacidade de medir } \\
\text { conhecimento por meio da } \\
\text { avaliação }\end{array}$ & Frequência & Percentual (\%) \\
\hline É capaz & 20 & 12,9 \\
\hline $\begin{array}{l}\text { É capaz a depender do tipo de } \\
\text { técnica utilizada }\end{array}$ & 39 & 25,2 \\
\hline $\begin{array}{l}\text { Não é capaz, pois pode não } \\
\text { trazer os temas específicos ao } \\
\text { qual o aluno se ateve }\end{array}$ & 36 & 23,2 \\
\hline $\begin{array}{l}\text { Não é capaz, por aspectos } \\
\text { emocionais negativos que } \\
\text { interferem no desempenho do } \\
\text { aluno }\end{array}$ & 15 & 9,7 \\
\hline $\begin{array}{l}\text { Depende da qualidade da } \\
\text { elaboração e dos critérios para } \\
\text { avaliação }\end{array}$ & 45 & 29,0 \\
\hline Total & 155 & $100 \%$ \\
\hline
\end{tabular}

Ademais, por meio da análise cruzada entre os dados sobre a capacidade da avaliação em medir o conhecimento adquirido (sétima pergunta do 
questionário) e a importância da avaliação em si (segunda pergunta do questionário), foi observado que: dos alunos que julgaram a avaliação importante apenas para o professor (sete discentes $-4,5 \%$ da amostra), 57,I4\% deles consideram que a mesma não é capaz de medir o conhecimento, pois não reflete os temas específicos estudados pelo aluno. Ao reconhecer a função burocrática e o caráter coercitivo do instrumento avaliativo, uma vez que serve apenas ao professor, estes alunos não percebem a avaliação como voltada para o discente, não exigindo, por isso, o conhecimento que o estudante considera como principal; ou seja, a avaliação não reflete o conhecimento do aluno porque não é voltada para o discente, mas para o sistema educacional.

Dos 15 estudantes que veem a avaliação como incapaz de refletir o conhecimento devido aos aspectos emocionais negativos, 53,3\% deles considera que a avaliação é importante apenas para o aluno, pois mede o seu desempenho. Assim, parece que o grau de nervosismo está ligado à importância dada à avaliação pelo aluno enquanto instrumento que define a sua capacidade de obter resultados significativos no ambiente educacional. Este comprometimento torna-se obrigação, gerando medo e frustração (LEITE; LIMA, 2008).

$29 \%$ da amostra do estudo (45 estudantes) considerou que a avaliação reflete o conhecimento a depender de como a prova é desenvolvida e como será avaliada. Neste contexto, 2I discentes ( $46,7 \%$ dos 45 estudantes) consideram a avaliação importante ao aluno como instrumento de desempenho e 20 estudantes ( $44,4 \%$ dos 45 estudantes) veem a importância para o aluno, mas também para o professor. Esta segunda percepção parece mais compatível com a compreensão de que o conhecimento será refletido ou não em uma avaliação também pela forma com que o docente organiza e estrutura este processo, servindo como mecanismo de avaliação da própria conduta e decisão tomada pelo professor. Por isso, a avaliação torna-se importante para ambos, gerando uma reflexão dos agentes do processo ensino-aprendizagem (SCHöN, 2000). Os dados cruzados destas questões analisadas são apresentados na Tabela 9. 
Tabela 9 Capacidade da avaliação em medir o conhecimento adquirido

\begin{tabular}{|c|c|c|c|c|c|c|}
\hline \multirow{2}{*}{\multicolumn{2}{|c|}{$\begin{array}{l}\text { Capacidade de medir } \\
\text { conhecimento }\end{array}$}} & \multicolumn{4}{|c|}{ Importância da avaliação } & \multirow[t]{2}{*}{ Total } \\
\hline & & B & C & D & $\mathbf{E}$ & \\
\hline A & 0 & 10 & 0 & 0 & 10 & 20 \\
\hline B & 1 & 22 & 1 & 0 & 15 & 39 \\
\hline C & 1 & 20 & 0 & 4 & 11 & 36 \\
\hline $\mathrm{D}$ & 0 & 8 & 0 & 2 & 5 & 15 \\
\hline $\mathrm{E}$ & 2 & 21 & 1 & 1 & 20 & 45 \\
\hline Total & 4 & 81 & 2 & 7 & 61 & 155 \\
\hline
\end{tabular}

\section{Relação ensino-aprendizagem}

De acordo com a realidade pesquisada, 54,8\% dos estudantes (total de 85) consideram que as avaliações são feitas de acordo com o que foi visto em sala, existindo algumas exceções. Outros 27,7\% (total de 43) afirmam que a avaliação a qual são submetidos, sem exceção, pede conhecimentos nos mesmos níveis e natureza apresentados em sala de aula. Esta consideração é importante, pois como revela Lewis (I99I), a percepção de que há divergência entre o conhecimento repassado em aula e o conhecimento cobrado no instrumento de avaliação faz com que os discentes considerem a avaliação falha, incompleta, ineficiente e inadequada.

Como afirma Godoy (2000), deve existir uma adequação entre o ensino ministrado e a avaliação, pressupondo que os resultados de aprendizagem solicitados pela avaliação estejam em harmonia com os objetivos educacionais pretendidos. Este quesito foi visto como satisfatório quando analisado os dados da pesquisa, considerando que apenas $17,4 \%$ (total de 27) da amostra observa que a avaliação pede conhecimentos acima do que foi visto em sala de aula. 


\section{CONSIDERAÇÕES FINAIS}

O presente artigo reconhece a complexidade que permeia o processo avaliatório da aprendizagem. Por meio da opinião e percepção do estudante, entretanto, acredita-se que é possível trazer importantes elementos para a reflexão sobre o tema, de modo a obter uma visão mais clara e que abarque todos os envolvidos nesta atividade.

Com base na pesquisa quantitativa aqui apresentada, foi propiciada uma descrição e compreensão mais acuradas acerca da avaliação sob a ótica do aluno. Os dados coletados e analisados revelaram que os estudantes de Administração da UFPE - CAA de maneira geral apontam as funções didáticas e burocráticas como motivos pelos quais se realiza uma avaliação. Estas percepções refletem uma prática tradicional de ensino onde a prova serve como instrumento de medição de desempenho do aluno, buscando atender as exigências burocráticas da Instituição. Resultante desta compreensão, a maioria da amostra analisada reconhece a importância da avaliação apenas para o estudante, não se mostrando relevante para todos os sujeitos que participam do processo de ensino e aprendizagem.

Estas duas considerações revelam a avaliação como se tem e não como se deseja. Uma avaliação formativa envolve a função de acompanhamento de ensino, que corresponde a uma reflexão do docente na e sobre sua ação (SCHÖN, 2000). Ademais, a percepção dos envolvidos no processo avaliativo deve estar pautada na evidência de que esta prática é importante para ambos, professor e aluno, ao gerar melhorias na postura e na prática educativa do docente e avanços na compreensão do conhecimento adquirido do aluno e sua necessidade de melhora.

A maioria dos alunos que compuseram a amostra afirma que os sentimentos em relação aos processos avaliativos variam de acordo com o quanto foi estudado, mas também estão ligados à empatia com a disciplina. Esta afirmação reflete um aspecto individual das horas de estudo, mas também um aspecto que transcende a individualidade, pois a empatia é influenciada pelo professor em si, pela forma como este ministra sua disciplina, como o conteúdo é transmitido e como é a relação entre professor e aluno. A interação 
constante, especialmente, parece ser componente norteador na avaliação como se deseja (GRILLO; GESSINGER, 20Io).

Em relação aos instrumentos mais comuns adotados por professores, os alunos citaram as provas escritas, os trabalhos e os seminários. Outros instrumentos, entretanto, foram citados pelos estudantes como preferidos por eles como, por exemplo, a participação e a presença em sala. São, portanto, aspectos mais informais, reforçados por Warren (I987) como tidos como relevantes para os estudantes. É importante pontuar que a diversificação dos instrumentos é necessária, pois garante que diversas habilidades sejam consideradas numa atmosfera de ensino onde cada discente apresenta sua maneira própria de mostrar o conhecimento adquirido (COVATTI; FISCHER, 20I2).

Ademais, foi identificado que o feedback dado pelos professores sobre a avaliação geralmente ocorre debatendo os resultados durante a aula. Ele surge como um instrumento de comunicação, motivação e aprendizagem (FLORES, 2009). Por conseguinte, os estudantes analisados apresentam discordâncias consideráveis em relação à capacidade da avaliação de medir o conhecimento, pois aspectos como nervosismo, estudo direcionado para temas não abordados na avaliação e má formulação dos seus instrumentos são vistos como barreiras para que este processo alcance um de seus objetivos - o da análise do nível de conhecimento do estudante. Por fim, a amostra reconheceu que há uma adequação entre o ensino ministrado e a avaliação, o que revela coerência do professor acerca do conhecimento repassado e, posteriormente, medido.

Conclui-se que, por meio desta análise, é possível desenvolver uma reflexão pluralizada sobre os processos de avaliação, conduzindo melhorias nas práticas educacionais e na formação e treinamento de professores universitários. Mais do que nunca, reconhece-se a necessidade de competência pedagógica do educador (MASETTO, 20I2). Com base no reconhecimento da percepção do aluno, melhores processos de ensino e aprendizagem podem ocorrer. Assim, sugere-se que outras pesquisas que envolvam a busca pela compreensão da percepção do aluno sejam realizadas, visando abranger mais especificamente alguns dos elementos que fazem parte do processo de avaliação, como, por exemplo, a interação entre professor e aluno neste cenário de Ensino Superior. 


\section{REFERÊNCIAS}

ALONSO, K. M. K. M. Formação de professores em exercício, educação a distância e a consolidação de um projeto de formação: o caso UFMT. 2005. 322f. Tese (Doutorado em Educação). Universidade Estadual de Campinas, Campinas, 2005.

BARBOSA, J.; ALAIZ, V. Instrumentos de avaliação: diversificar é preciso. In: I.I.E. (Ed.). Pensar Avaliação, Melhorar a Aprendizagem. Lisboa: I.I.E, 1994.

BITENCOURT, B. M.; SEVERO, M. B.; GALLON, S. Avaliação da aprendizagem no Ensino Superior: desafios e potencialidades na educação a distância. Revista Eletrônica de Educação, v. 7, n. 2, p. 211-226, 2013.

BOUD, D. Assessment and the promotion of academic values. Studies in Higher Education, v. 15, n. 1, p. 10-11, 1990.

COVATTI, F. A.; FISCHER, J. Reflexões sobre a avaliação da aprendizagem: diversidade e inclusão escolar. Revista Educação Especial, v. 25, n. 43, p. 305-318, 2012.

COX, R. Higher education: assessment of students. In: HUSÉN, T.; POSTLETHWAITE, T. N. The International Encyclopedia of Education. Oxford: Pergamon Press, v. 4, 1985, p. 86-93.

FERNANDES, D. Avaliar para aprender: fundamentos, práticas e políticas. São Paulo, SP: EdUNESP, 2009.

FLORES, A. M. O feedback como recurso para motivação e avaliação da aprendizagem na educação a distância. In: CIAED, Congresso Internacional Abed de Educação à Distância, 15., Fortaleza/CE, 2009.

GODOY, A. S. Avaliação da aprendizagem: a ótica de alunos e professores universitários. Rio Claro: UNESP/Departamento de Educação, 1995.

GODOY, A. S. Avaliação da aprendizagem no ensino superior: um estudo exploratório a partir das opiniões dos alunos do primeiro e do último ano de três cursos de graduação. Revista Administração online, v.1, n.1, p. 28-40, 2000.

GONÇALVES, I. G. C. A importância da avaliação da aprendizagem e a avaliação institucional para a qualidade do ensino superior no Brasil. In: VII Encontro de Produção Científica e Tecnológica, 2012.

GRILLO, M. C.; GESSINGER, R. M. Por que falar ainda em avaliação? Porto Alegre: EDIPUCRS, 2010.

LEITE, A. C. T.; LIMA, C. A. Avaliação como Motivação para Aprendizagem. Associação Nacional dos Cursos de Graduação em Administração, 2008. Disponível em: $<$ http://www.angrad.org.br/area_cientifica/artigos/avaliacao_como_motivacao_para_ aprendizagem/574/> Acesso em: 23/06/2014.

LEWIS, K. G. Gathering data for the improvement of teaching: what do I need and how do I get it? New Directions for Teaching and Learning, n. 48, p. 65-82, 1991. 
MARINHO, P.; FERNANDES, P.; LEITE, C. A avaliação da aprendizagem: da pluralidade de enunciações à dualidade de concepções. Acta Scientiarum, v. 36, n. 1, p. 151-162, 2014.

MARINHO, P.; LEITE, C.; FERNANDES, P. Avaliar para classificar ou aprender? Da interação à ação. In: ESTRELA, T. et al (ed.). Revisitar os estudos curriculares: onde estamos e para onde vamos. Lisboa: Atas do XIX Colóquio EDUCA/Secção Portuguesa da AFIRSE, 2012, p. 1476.

MASETTO, M. T. Competência pedagógica do professor universitário. 2.ed. São Paulo: Summus, 2012.

PERRENOUD, P. Avaliação: da excelência à regulação das aprendizagens - entre duas lógicas. Porto Alegre: Artmed, 1999.

RABELO, E. H. Avaliação: novos tempos, novas práticas. 2.ed. Petrópolis/RJ: Vozes, 1998.

RIOS, M. P. G. A avaliação formativa como procedimento de qualificação docente. Revista E-Curriculum, v. 1, n. 1, 2005-2006.

ROBBINS, S. Comportamento Organizacional. São Paulo: Pearson Prentice Hall, 2005.

SCHÖN, D. A. Educando o profissional reflexivo: um novo design para o ensino e a aprendizagem. Porto Alegre: Artes Médicas Sul, 2000.

SCRIVEN, M. The methodology of evaluation. American Educational Research Association Monograph series on curriculum evaluation, v. 1, n.1, p. 29-83, 1967.

SOUZA, N.A.; BORUCHOVITCH, E. Avaliação da aprendizagem e motivação para aprender: tramas e entrelaços na formação de professores. Educação Temática Digital, n. 10, p. 204-227, 2009.

UFPE. CAA. Disponível em: < http://www.ufpe.br/caa/index.php?option=com_contentev $i e w=$ articled $i d=55 \&$ Itemid $=71>$. Acesso em: 27/06/2014.

WARREN, J. Assessment at source: What is assessment and why are we so obsessed with it? Liberal Education, v. 73, n. 3, p. 2-6, 1987. 


\section{APÊNDICE A}

\section{QUESTIONÁRIO - PESQUISA SOBRE AVALIAÇÃO}

Curso de Graduação: Administração

Gênero: a) masculino b) feminino

Idade:

Período do aluno:

I. Na sua opinião, quais os motivos para os professores avaliarem os alunos?

a) Para saber se os alunos estão ou não entendendo a matéria dada; para avaliar o grau de conhecimento.

b) Porque o professor precisa apresentar uma nota do aluno para a Universidade, precisa seguir as normas de ensino.

c) Para avaliar a si próprios, ou seja, até onde o professor consegue alcançar o aluno, ver se sua forma de ensinar está surtindo efeito.

d) Porque é a única maneira de prender a atenção dos alunos, fazê-los terem interesse.

e) Para analisar se o aluno aprendeu e, no futuro, não ser um mau profissional.

2. Para você, a avaliação:

a) Não é importante.

b) É importante para o próprio aluno, pois possibilita avaliar seu próprio desempenho.

c) É importante para o próprio aluno, pois possibilita ter um currículo melhor.

d) É importante apenas para o professor.

e) É importante para aluno e professor.

3. Qual o seu sentimento a respeito do processo avaliatório?

a) Tenho um sentimento negativo. Fico nervoso(a), angustiado(a)... Sinto-me pressionado(a).

b) Tenho um sentimento negativo. Fico com raiva, pois não concordo com certas formas de avaliação.

c) Meus sentimentos variam, pois dependem do quanto estudei e se gosto da disciplina.

d) Tenho sentimento positivo. A avaliação é apenas uma atividade normal, tranquila, que se constitui em mais uma na rotina.

e) Tenho sentimento positivo. Gosto das formas de avaliação dos professores e me sinto motivado(a) a realizá-las.

4. Qual a forma mais comum de avaliação aplicada pelo professor durante sua graduação?

a) Provas escritas. b) Trabalhos (relatórios, projetos e pesquisas).

c) Seminários.

d) Provas orais.

e) Participação e frequência nas aulas.

5. Qual sua forma de avaliação preferida?

a) Provas escritas.

b) Trabalhos (relatórios, projetos e pesquisas).

c) Seminários.

d) Provas orais.

e) Participação e frequência nas aulas.

6. Em geral, qual o comportamento dos professores após correção da prova?

a) Os professores discutem as questões da prova e falam a nota do aluno.

b) Os professores discutem as questões da prova, mas não falam a nota, apenas colocam no SIGA.

c) Os professores apenas falam a nota.

d) Os professores entregam a prova aos alunos e aguardam dúvidas e questionamentos.

e) Os professores não discutem as questões da prova nem falam a nota do aluno em sala.

7. A avaliação:

a) Na maioria das vezes é capaz de refletir o conhecimento aprendido.

b) É capaz de refletir o conhecimento aprendido a depender do tipo de técnica avaliativa escolhida pelo professor.

c) Não reflete os conhecimentos adquiridos, pois às vezes os alunos se dedicam a temas específicos no momento do estudo que podem não cair em prova.

d) Geralmente não reflete o conhecimento, pois aspectos como nervosismo atrapalham.

e) Refletem ou não o conhecimento a depender da qualidade das questões, da elaboração e da avaliação do professor.

8. A avaliação aplicada pelo professor:

a) Pede conhecimentos nos mesmos níveis e natureza apresentados em sala de aula.

b) São feitas de acordo com o que foi visto em sala, existindo algumas exceções.

c) Pede conhecimentos acima do que foi visto em sala de aula. 
AVALIAÇÃO DA APRENDIZAGEM: UM ESTUDO COM BASE NAS PERCEPÇÕES DOS ALUNOS DO CURSO DE GRADUAÇÃO EM ADMINISTRAÇÃo

1 Dados obtidos internamente na Instituição. 


\section{DADOS DOS AUTORES}

\section{MARIANNY JESSICA DE BRITO SILVA^ marianny.jbrito@gmail.com} Mestre em Administração pela UFPE

Instituição de vinculação: Universidade Federal de Pernambuco Recife/PE - Brasil

Áreas de interesse em pesquisa: Ensino e Aprendizagem em Administração e Marketing.

${ }^{\star}$ Rua Manoel Nunes Filho, 186, apto. 102B Caruaru-PE. 55024-320.

\section{RAQUEL SOUZA RAMOS raquel_souza.adm@hotmail.com} Mestre em Administração pela UFPE

Instituição de vinculação: Universidade Federal de Pernambuco Recife/PE - Brasil

Áreas de interesse em pesquisa: Finanças e Ensino e Aprendizagem em Administração. 